\title{
Ankilozan Spondilit, Crohn Hastalığı ve Anti-tümör Nekroz Faktör- alfa Tedavi ile Indüklenen Psoriasis olan Hastada Ustekinumab Tedavisine Dramatik Yanıt
}

\author{
Dramatic Response to Ustekinumab Treatment in a Patient with Ankylosing Spondylitis \\ and Crohn's Disease and Anti-tumor Necrosis Factor-alpha Drug Induced Psoriasis
}

(D) Sevilay Kılıç, (D) Hatice Reşorlu*, (D) Alper Ekinci, (D) Ayşe Selcen Bulut Keskin*

Çanakkale Onsekiz Mart Üniversitesi Tıp Fakültesi, Dermatoloji Anabilim Dalı, Çanakkale, Türkiye

*Çanakkale Onsekiz Mart Üniversitesi Tıp Fakültesi, Fiziksel Tip ve Rehabilitasyon Anabilim Dalı, Çanakkale, Türkiye

\section{Öz}

Anti-tümör nekroz faktör-alfa (anti-TNF- $\alpha$ ) ilaçlar ile tedavi, Crohn hastalığı, ankilozan spondilit ve psoriasis dahil olmak üzere, ortak patogeneze sahip olan birçok kronik enflamatuvar hastalıkta önemli iyileşme sağlar. Ancak bu tedaviler esnasında, paradoksal olarak, psoriasis gibi kütanöz yan etkiler görülebilmektedir. Patofizyolojisi halen tam olarak anlaşılamamasına rağmen, TNF- $\alpha$ blokajının yatkın kişilerde lokal olarak aşırı interferon- $\alpha$ üretimini tetiklediği ve psoriatik lezyonlara neden olduğu düşünülmektedir. Bu olguda ankilozan spondilit ve Crohn hastalı̆̆ı nedeniyle, önce adalimumab sonrasında infliksimab kullanan ve bu ilaçlara bağlı psoriasiform lezyonları gelişen, 50 yaşında kadın hastamızı sunduk. Anti-TNF- $\alpha$ tedavisi kesilen ve ustekinumab başlanan hastada, tedaviye dramatik bir yanıt alınmıştır. Psoriasiform döküntüler düzelmiş, ankilozan spondilit ve Crohn hastalığına ait hastalık aktivitesi baskılanmıştır. Ustekinumab, anti-TNF- $\alpha$ ilaçlara bağlı psoriasiform döküntüler gelişen, ankilozan spondilit ve Crohn hastalarının yönetiminde iyi bir seçenek olabilir.

Anahtar kelimeler: Psoriasis, Crohn hastalığı, ankilozan spondilit, ustekinumab

\section{Abstract}

Treatment with anti-tumour necrosis factor-alpha (anti-TNF- $\alpha$ ) drugs provides significant improvements in many chronic inflammatory diseases with common pathogenesis, including Crohn's disease, ankylosing spondylitis and psoriasis. However, during these treatments, paradoxically, cutaneous side effects such as psoriasis can be seen. Although its pathophysiology is well understood, it is thought that TNF- $\alpha$ blockade triggers locally excessive interferon- $\alpha$ production in predisposed subjects and causes psoriatic lesions. In this case report, we present a 50 -yearold female patient with ankylosing spondylitis and Crohn's disease who used adalimumab and then infliximab and developed psoriasiform lesions due to these drugs. Anti-TNF- $\alpha$ treatment was discontinued, and ustekinumab was started. Psoriasiform rashes improved; disease activity of ankylosing spondylitis and Crohn's disease was suppressed. Ustekinumab may be a good option to manage ankylosing spondylitis and patients with Crohn's disease who develop psoriasiform rashes due to anti-TNF- $\alpha$ drugs.

Keywords: Psoriasis, Crohn's disease, ankylosing spondylitis, ustekinumab

\section{Giriş}

Psoriasis, multipl komorbiditeleri olan multisistem, kronik enflamatuvar bir hastalıktır. Psoriasisin; obezite, metabolik sendrom, hipertansiyon, diyabet, ateroskleroz, seronegatif spondiloartrit ve enflamatuvar barsak hastalığı gibi ortak patogenetik mekanizmayı paylaşan birçok hastalık ile ilişkili olduğu bilinmektedir. Psoriasis ve pek çok enflamatuvar romatizmal hastalığın tedavisinde anti-tümör nekroz faktör-alfa (anti-TNF- $\alpha$ ) ilaçlar uzun süreden beri kullanılmaktadır. Ancak bu ilaçların, bazen beklenmedik şekilde psoriasiform döküntülere yol açtığı görülmektedir. Son zamanlarda anti-TNF- $\alpha$ tedavisi ile indüklenen psoriasis olgularında, önemli sayıda olgu bildirilmiştir (1-3). Bununla birlikte, paradoksal görülen bu yan etkinin, patojenik mekanizması henüz tam olarak anlaşılamamıştır. Bir biyolojik tedavi olan ustekinumab, IL-12 ve IL-23 sitokinlerin ortak p40 alt birimlerini etkileyen bir lg G1 rekombinant monoklonal antikorudur. Orta-şiddetli plak tip psoriasis tedavisinde etkili ve güvenli olduğu kanıtlanmıştır (4). Ayrıca ankilozan spondilit (AS) ve enflamatuvar barsak hastalığında da kullanımı söz konusudur $(5,6)$.

Yazışma Adresi/Address for Correspondence: Dr. Hatice Reşorlu, Çanakkale Onsekiz Mart Üniversitesi Tıp Fakültesi, Fiziksel Tıp ve Rehabilitasyon Anabilim Dalı, Çanakkale, Türkiye 
Bu olguda; AS ve Crohn hastalığı (CH) ile takip edilen hastamızda, anti TNF- $\alpha$ tedavisi sonrası gelişen psoriasis ve ustekinumab tedavisine verdiği dramatik yanıt sunulmuştur. Ustekinumab tedavisi ile hem psoriasis, hem de AS ve $\mathrm{CH}$ kontrol altına alınmıştır.

\section{Olgu Sunumu}

Elli yaşında, $\mathrm{CH}$ ve AS tanıları ile takip edilen kadın hasta polikliniğimize kol ve bacakta döküntüler ile başvurdu. Özgeçmişinde, diabetes mellitus, hipertansiyon ve tiroid nodülleri mevcuttu. Sigara ve alkol kullanımı yoktu. Soygeçmişinde, annesinde psoriasis ve çocuğunda $\mathrm{CH}$ olduğu öğrenildi. Daha önce, $\mathrm{CH}$ ve AS tedavisi için non-steroid anti-enflamatuvar ilaçlar, sulfasalazin, prednizolon, metotreksat ve azatiopirin kullandığı öğrenildi. Ancak her iki hastalık için de etkisizlik nedeni ile adalimumab tedavisine geçilmişti. Bu tedavi sonrasında, kol ve bacak ekstansör bölgelerinde psoriatik lezyonlar gelişmişti. Muayenesinde, saçlı deri, gövde, alt ve üst ekstremitede yaygın psoriatik plaklar gözlendi. Psoriasis alan şiddet indeksi (PASI) skoru 17,5 olarak bulundu. Laboratuvar değerleri, hafif hiperglisemi (açlık kan şekeri $132 \mathrm{mg} / \mathrm{dL}$ ) haricinde normaldi. Bath Ankilozan Spondilit Hastalık Aktivite indeksi (BASDAI): 7,2'ydi. Bunun üzerine infliksimab tedavisine geçildi. Ancak tedavinin 3. ayında ne psoriasis lezyonlarında (PASI skorları) ne eklem şikayetlerinde, (BASDAI skorları) ne de gastrointestinal sistem şikayetlerinde (karın ağrısı, ishal) iyileşme olmadı (Şekil 1). Tedavi devam ederken mevcut 3 hastalığında da kötüleşme olması üzerine, hasta gastroenteroloji ve dermatoloji ile konsülte edildi. Ustekinumab tedavisi başlanması uygun görüldü. Hastanın kilosuna uygun olarak 12 haftada bir 90 mg ustekinumab verildi $(0,4$ ve 12. haftalarda indüksiyon tedavisi yapıldı). Tedavinin 3 . ayında PASI ve BASDAI skorlarının gerilediği, periferik artrit ve kanlı ishal şikayetlerinin de kaybolduğu görüldü (Şekil 2). Birinci yılın sonunda psoriasis lezyonları tamamen iyileşti $(P A S I=0)$ ve BASDAI skoru 2'nin altına indi.

Hasta onamı alınmıştır.

\section{Tartışma}

Anti TNF- $\alpha$ ilaçlar, spondilartropatilerin tedavisinde sık tercih edilen, etkinliği kanıtlanmış ilaçlardır. Bu tedaviler esnasında,

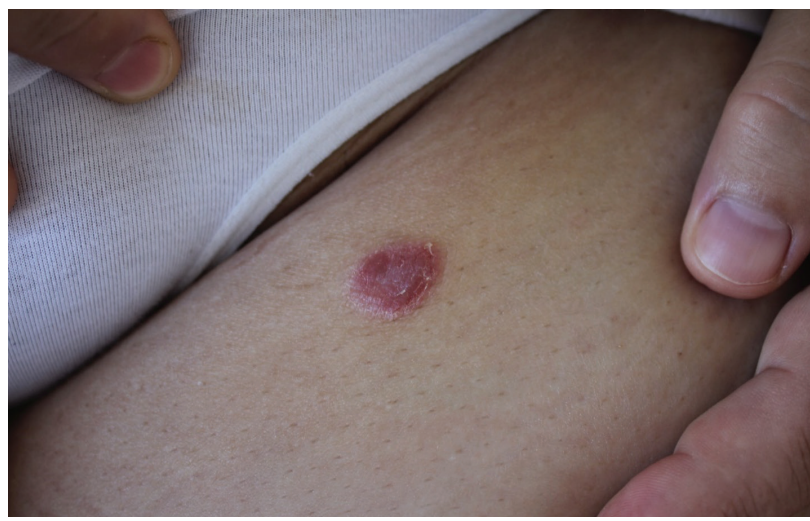

Şekil 1. Alt ekstremitede psoriatik plaklar literatürde iyi tanımlanmış yan etkilerin yanı sıra; bazı paradoksal yan etkiler de görülebilir. Psoriasis bu paradoksal yan etkilerin en bilinenidir. Psoriasis dışı endikasyonlarla anti TNF- $\alpha$ kullanan hastalarda, yeni oluşan psoriatik lezyonlar şeklinde görülebileceği gibi; psoriasis tanılı hastalarda lezyonlarda alevlenme şeklinde de ortaya çıkabilir $(7,8)$. Bu durumun patofizyolojisi henüz net olarak açıklanamamakla birlikte, bazı hipotezler öne sürülmektedir. En sık kabul gören hipotez interferon (IFN)- $\alpha$ ile ilgilidir. IFN- $\alpha$ psoriasis indüksiyonunun erken evresi için önemli bir sitokindir. Dermal plazmositoid dendritik hücreler (DPDC), IFN- $\alpha$ üretiminde görev alır. TNF- $\alpha$, DPDC etkileyerek, IFN- $\alpha$ üretimini inhibe edebilir. TNF- $\alpha$ blokajı ile, predispoze kişilerde lokal olarak aşırı IFN- $\alpha$ üretimi oluşur. Bu durumun IL15/bazı kemokin reseptörlerinde (CXCR3) artış yoluyla, T hücrelerini aktive ettiği ve sonuçta deriye migrasyonuna neden olarak psoriatik lezyonları oluşturduğu düşünülmektedir $(9,10)$.

Bazı yazarlar; genetik faktörlerin psoriasis gelişiminde önemli bir rol oynadığını öne sürmektedir. Genetik polimorfizmlerin, paradoksal psoriatik lezyonları oluşturduğu düşünülmektedir $(11,12)$. Sherlock ve ark. (13) derlediği bir retrospektif çalışmada; infliksimab tedavisi sonrası psoriasis ve psoriasiform deri lezyonları gelişen hastalarda, IL23R'deki polimorfizmler ile $\mathrm{CH}$ arasında bir ilişki bulunmuştur.

Psoriasiform reaksiyonlar, kadınlarda ve kişisel/ailesel psoriasis öyküsü olmayan hastalarda daha sık görülmektedir (14). Olguların çoğunda, döküntülerin, anti TNF- $\alpha$ tedavinin 3. ve 4. enjeksiyonlarında geliştiği gözlenir. Ancak ilacın ilk

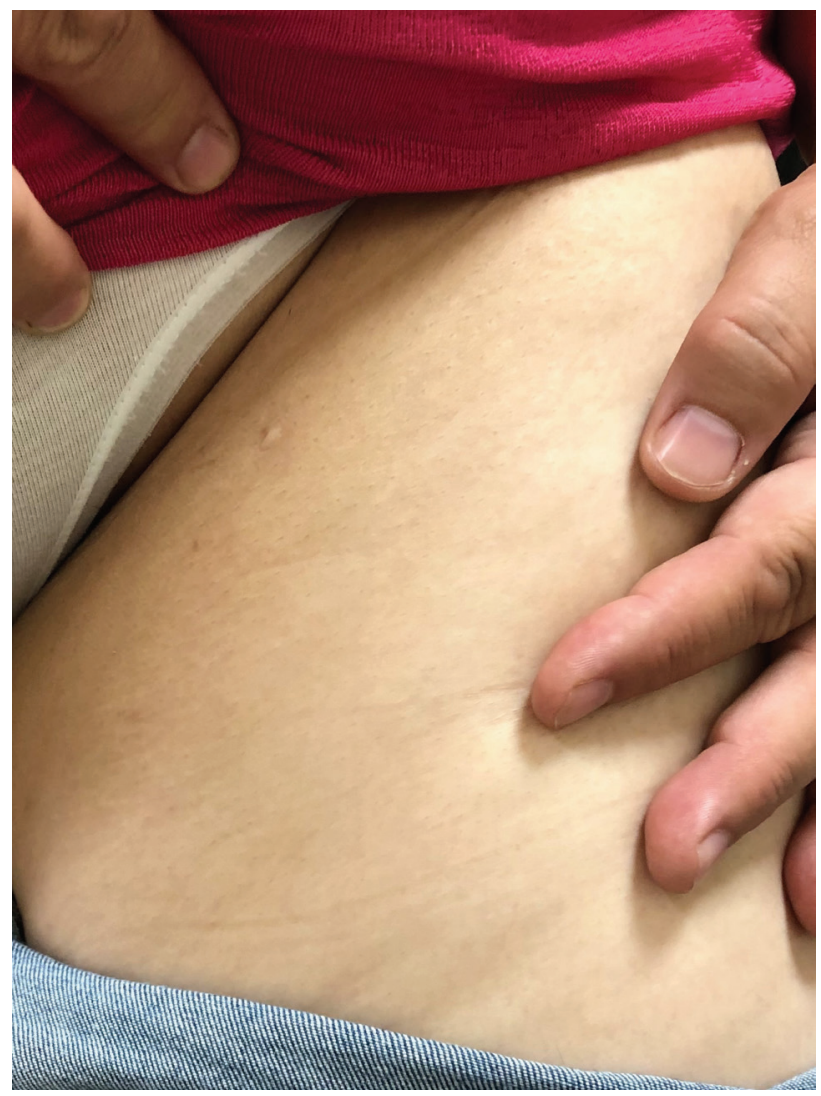

Şekil 2. Alt ekstremitede tamamen iyileşmiş psoriatik plaklar 
uygulanmasından günler sonra ya da 7 yıl sonrasında görülen olgular da bildirilmiştir $(15,16)$. Bilinen olguların yaklaşık yarısı infliksimab ile ilişkilidir (14-16). Harrison ve ark. (10), psoriasiform lezyonları en çok indükleyen anti-TNF- $\alpha$ ilacın, adalimumab olduğunu bildirmektedirler. Bizim hastamızda olduğu gibi, farklı anti-TNF- $\alpha$ ilaçlara karşı, aynı yan etkiye sahip olan hastalar da mevcuttur (16)

Psoriasis tedavisi sırasında gelişen yeni psoriasiform döküntüler, önceki lezyonlardan farklı lokalizasyonlarda (en sık palmoplantar lokalizasyonda) ve farklı morfolojide görülmektedir (en sık püstüler tip) $(9,17)$. Bu veriler, anti-TNF- $\alpha$ ile tedavi sonrası gelişmiş psoriasiform lezyonların önceden var olan psoriasisin kötüleşmesi olmadığı aksine de novo psoriasis olduğunu desteklemektedir $(17,18)$. Bizim hastamıda da ilk olarak adalimumab kullanımı ile gelişen, sonrasında infliksimab kullanımıyla devam eden ve artış gösteren psoriasiform lezyonlar vardı. Kişisel/ailesel psoriasis öyküsü yoktu. Literatürden farklı olarak; yeni gelişen psoriasis lezyonları plak tip psoriasis formundaydı ve lokalizasyonu plak tip psoriasisde görülen tipik lokalizasyonla uyumluydu.

Paradoks olarak tetiklenen psoriasis olgularının yönetiminde, olağan psoriasis olgularından farklı bir öneri bulunmamaktadır. Vücut yüzeyinin \%5'inden azını içeren psoriasiform lezyonları olan hastalarda topikal tedavilerin (glukokortikoidler, kalsinörin inhibitörleri ve antibiyotikler) kullanılması ve anti-TNF- $\alpha$ ile tedaviye devam edilmesi önerilmektedir. Ancak vücut yüzey alanının \%5'inden fazlasını içeren lezyonları olan şiddetli tutulum gösteren hastalarda, anti-TNF- $\alpha$ kullanımına ara verilmeli, sistemik tedaviler (fototerapi, asitretin, glukokortikoidler ve antibiyotikler) kullanılmalı, veya hastanın durumuna bağlı olarak başka bir biyolojik ajana geçilmesi düşünülmelidir $(12,17)$. Bizim olgumuzda psoriasis lezyonlarının artış göstermesine ek olarak, mevcut diğer iki hastalığının da kötüleşmesi nedeniyle antiTNF- $\alpha$ tedavisi kesilerek farklı bir biyolojik ajan olan ustekinumab tedavisi başlandı. Bu tedavi ile hem psoriasis hem de AS ve $\mathrm{CH}$ kontrol altına alınabildi. Hastanın $\mathrm{CH}$ için kullandığı mesalazin ve azotiopürin kesildi.

Literatürde, anti-TNF- $\alpha$ intoleransı olan ve psoriasiform döküntüleri gelişen hastaların yönetiminde, ustekinumab iyi bir seçenek gibi görünmektedir. Gözlemimize göre; ustekinumab, anti-TNF- $\alpha$ ajanların tetiklediği psoriasis, $\mathrm{CH}$ ve AS bulunan hastamızda iyi bir tedavi seçeneği olmuştur. Bu anlamda her üç hastalığında etkin tedavi edildiği ilk olgudır. Bizim olumlu sonuçlarımıza rağmen, nadiren ustekinumab tedavisi ile de psoriasiform yan etkiler bildirilmiştir $(19,20)$.

Psoriasis, AS ve $\mathrm{CH}$ gibi birçok kronik enflamatuvar hastalıkla ortak bir patogeneze sahiptir. Bu hastalıkların tedavisinde kullanılan anti-TNF- $\alpha$ tedaviler, paradoksal olarak psoriasis oluşumuna neden olabilirler. Böyle bir durumda, hastanın durumuna bağlı olarak, ilacın kullanımına ara vermek, başka bir biyolojik ajan ile tedaviye geçmek ya da psoriasis için ek bir hastalık modifiye edici ajan eklemek gibi tedaviler düşünülebilir. Bu anlamda ustekinumab etkin bir tedavi seçeneği olabilir. Ancak; paradoksal olarak gelişen psoriasisin, klinik özelliklerinin ve patofizyolojisinin daha iyi anlaşılabilmesi ve uygun bir şekilde tedavi edilebilmesi için benzer olgularla daha ileri çalışmalar yapılması gereklidir.

\section{Etik}

Hasta Onayı: Hasta onamı alınmıştır.

Hakem Değerlendirmesi: Editörler kurulu ve editörler kurulu dışında olan kişiler tarafından değerlendirilmiştir.

\section{Yazarlık Katkıları}

Cerrahi ve medikal uygulamalar: S.K., A.E., Konsept: S.K., A.E., Dizayn: S.K., A.E., A.S.B.K., Veri toplama veya işleme: H.R., A.S.B.K., Analiz veya yorumlama: A.S.B.K., Literatür arama: H.R., A.S.B.K., Yazma: H.R., S.K.

Çıkar Çatışması: Yazarlar tarafından çıkar çatışması bildirilmemiştir.

Finansal Destek: Yazarlar, bu çalışma için herhangi bir finansal destek almadıklarını bildirmiştir.

\section{Kaynaklar}

1. Nidegger A, Mylonas A, Conrad C. Paradoxical psoriasis induced by anti-TNF - $\alpha$ clinical challenge. Rev Med Suisse 2019;15:668-71.

2. Ciccarelli F, De Martinis M, Sirufo MM, Ginaldi L. psoriasis induced by anti-tumor necrosis factor alpha agents: a comprehensive review of the literature. Acta Dermatovenerol Croat 2016;24:169-74.

3. Guerra I, Pérez-Jeldres T, Iborra M, Algaba A, Monfort D, Calvet $X$, et al. Incidence, clinical characteristics, and management of psoriasis induced by anti-TNF therapy in patients with inflammatory bowel disease. Inflamm Bowel Dis 2016;22:894-901.

4. Papp KA, Langley RG, Lebwohl M, Krueger GG, Szapary $P_{\text {, }}$ Yeilding $N$, et al. Efficacy and safety of ustekinumab, a human interleukin-12/23 monoclonal antibody, in patients with psoriasis: 52-week results from a randomised, double-blind, placebocontrolled trial (PHOENIX 2). Lancet 2008;371:1675-84.

5. Sandborn WJ, Feagan BG, Fedorak RN, Scherl E, Fleisher MR, Katz $S$, et al. A randomized trial of Ustekinumab, a human Interleukin-12/23 monoclonal antibody, in patients with moderateto-severe Crohn's disease. Gastroenterology 2008;135:1130-41.

6. Kavanaugh A, Puig L, Gottlieb AB, Ritchlin C, You Y, Li S, et al. Efficacy and safety of ustekinumab in psoriatic arthritis patients with peripheral arthritis and physician-reported spondylitis: post-hoc analyses from two phase III, multicentre, double-blind, placebo-controlled studies (PSUMMIT-1/PSUMMIT-2). Ann Rheum Dis 2016;75:1984-8.

7. Boyman O, Comte D, Spertini F. Adverse reactions to biologic agents and their medical management. Nat Rev Rheumatol 2014;10:61227.

8. Barthel C, Biedermann L, Frei P, Vavricka SR, Kündig T, Fried M, et al. Induction or exacerbation of psoriasis in patients with Crohn's disease under treatment with anti-TNF antibodies. Digestion 2014;89:209-15.

9. Collamer AN, Battafarano DF. Psoriatic skin lesions induced by tumor necrosis factor antagonist therapy: clinical features and possible immunopathogenesis. Semin Arthritis Rheum 2010;40:233-40.

10. Harrison MJ, Dixon WG, Watson KD, King Y, Groves R, Hyrich KL, et al. Rates of new-onset psoriasis in patients with rheumatoid arthritis receiving anti-tumour necrosis factor therapy: results from the British Society for Rheumatology Biologics Register. Ann Rheum Dis 2009;68:209-15.

11. Collamer AN, Guerrero KT, Henning JS, Battafarano DF. Psoriatic skin lesions induced by tumor necrosis factor antagonist therapy: A literature review and potential mechanisms of action. Arthritis Rheum 2008;59:996-1001.

12. Ko JM, Gottlieb AB, Kerbleski JF. Induction and exacerbation of psoriasis with TNF-blockade therapy: a review and analysis of 127 cases. J Dermatolog Treat 2009;20:100-8. 
13. Sherlock ME, Walters T, Tabbers MM, Frost $K$, Zachos M, Muise $A$, et al. Infliximab-Induced Psoriasis and Psoriasiform Skin Lesions in Pediatric Crohn Disease and a Potential Association With IL-23 Receptor Polymorphisms. J Pediatr Gastroenterol Nutr 2013;56:512-8.

14. Harrison MJ, Dixon WG, Watson KD, King Y, Groves R, Hyrich KL, et al. Rates of new-onset psoriasis in patients with rheumatoid arthritis receiving anti-tumour necrosis factor therapy: results from the British Society for Rheumatology Biologics Register. Ann Rheum Dis 2009;68:209-15.

15. Severs GA, Lawlor TH, Purcell SM, Adler DJ, Thompson R. Cutaneous adverse reaction to infliximab: report of psoriasis developing in 3 patients. Cutis 2007;80:231-7

16. Takahashı H, Hashımoto $Y$, Ishıda-Yamamoto A, Ashıda T, Kohgo $Y$, Iızuka H. Psoriasiform and pustular eruption induced by infliximab. J Dermatol 2007;34:468-72.
17. Iborra M, Beltrán B, Bastida G, Aguas M, Nos P. Infliximab and adalimumab-induced psoriasis in Crohn's disease: A paradoxical side effect. J Crohn's Colitis 2011;5:157-61.

18. Joyau C, Veyrac G, Dixneuf V, Jolliet P. Anti-tumour necrosis factor alpha therapy and increased risk of de novo psoriasis: is it really a paradoxical side effect? Clin Exp Rheumatol 2012;30:700-6.

19. Lee $\mathrm{HY}$, Woo $\mathrm{CH}$, Haw S. Paradoxical flare of psoriasis after ustekinumab therapy. Ann Dermatol 2017;29:794-5.

20. Suh HY, Ahn JY, Park MY, Youn Jl. Exacerbation of infliximabinduced paradoxical psoriasis after ustekinumab therapy. J Dermatol 2018;45:332-3. 